\title{
Does the phenotypic morphology of the human brachial plexus reflect the theoretical development of concomitant regulation in thoracolumbar spines and nerves?
}

\author{
T. Kawashima®D, K. Ishiguro, F. Sato \\ Department of Anatomy, School of Medicine, Toho University, Tokyo, Japan
}

[Received: 15 July 2021; Accepted: 10 September 2021; Early publication date: 15 September 2021]

\begin{abstract}
Background: Experimental evidence identified that thoracolumbar mutants caused by Hox genes 7-10 mutants also involve a craniocaudal shift and/or the addition or reduction of segments of the limb plexus roots. This study investigated whether the theoretical concomitant shift of the brachial plexus roots in human different thoracolumbar counts is shared as confirmed in those of the human lumbosacral plexus.
\end{abstract}

Materials and methods: The phenotypic morphology of the brachial plexus and its arterial interaction on 20 sides of 10 atypical human thoracolumbar counts out of the 354 sides of the 177 cadavers, were compared with those of 52 sides of 26 cases in a typical human vertebral formula (7C_12T_5L_5S).

Results: Regardless of the course and branching patterns of the axillary artery, our results showed that the main brachial plexus roots were composed of only five segments of the $5^{\text {th }}-9^{\text {th }}$ spinal nerves, with small contributions from the $4^{\text {th }}$ and/or $10^{\text {th }}$ nerves. This root composition is identical to a typical human thoracolumbar formula, and therefore, neither a craniocaudal shift nor additional/reduced main roots occurred in our thoracolumbar variants.

Conclusions: Unlike the concomitant shift of the lumbosacral plexus roots, our present cases suggest that the phenotypic morphology of the human brachial plexus may be less likely to show theoretical craniocaudal shifts, further data on the root changes in different vertebral formulae are needed for its accurate validation. (Folia Morphol 2022; 81, 4: 884-899)

Key words: thoracolumbar mutant, brachial plexus, human development, anatomy, phenotypic morphology, vertebral formula

\section{INTRODUCTION}

Experimental embryology has identified the vertebral count and formula regulated by Hox genes: HOXA-7, HOXC-8, and HOXC-9 intensely regulate the upper, middle, and lower thoracic vertebrae respectively, and their mutants exhibit homeotic trans- formations with vertebral shifts in the axial skeleton [31]. They also regulate the vertebral junctions: HOX-6 genes are known to have expression boundaries around the neck/thorax junction; HOX-10 genes are expressed at the boundary between the thoracic and lumbar junctions, and HOX-11 genes are expressed

Address for correspondence: Dr. T. Kawashima, Department of Anatomy, School of Medicine, Toho University, Japan. 5-21-16 Omori-Nishi, Ota-ku, Tokyo 143-8540, Japan, tel: +81-3-3762-4151, fax: +81-3-5493-5411, e-mail: tomokazu.kawashima@med.toho-u.ac.jp

This article is available in open access under Creative Common Attribution-Non-Commercial-No Derivatives 4.0 International (CC BY-NC-ND 4.0) license, allowing to download articles and share them with others as long as they credit the authors and the publisher, but without permission to change them in any way or use them commercially. 
between the lumbar and sacral junctions $[13,45]$. However, their regulation domains overlap with adjacent Hox genes: Hox genes 5-7 regulate domains that overlap in the vertebral segments in the middle cervical to the upper thoracic vertebrae, and HOX 9-11 have domains that overlap in the vertebral segments from the lower lumbar to the sacral vertebrae $[14,45]$. In other words, each Hox gene is crucial for identifying the vertebral count, formula, and boundaries; however, they co-regulate a wide range of overlapping domains. In atypical thoracolumbar counts in adult cadavers, it is difficult to retrospectively determine causative Hox mutants.

Moreover, Hox genes regulate concomitant development of the vertebrae and spinal nerves [13-15], and the same Hox genes are expressed in the same domains in mice, chicks, and humans $[14,27,30]$. A previous study reported a caudal shift of the lumbar plexus roots in HOXA-9 and -10 mutant mice, which resulted in changes to the thoracic vertebra with additional ribs from the first lumbar vertebra $[17,40]$. On the other hand, several anatomical studies on the spinal segment transformations of the lumbar plexus root have been performed in one additional or reduced human thoracolumbar count $[5,34,37]$. However, the craniocaudal shift changes were unclear due to the range of variation shown in a typical human lumbar plexus roots, where one additional or reduced thoracolumbar count was considered a typical variation. This issue on anatomical normality and variability have been deeply debated in the long history of anatomy [49]. One additional or reduced thoracolumbar count is often observed within the normal range, so each anatomical normality and variability may not be easy to identify among their overlapping variation based on this concept. We recently performed a postmortem anatomical study on the phenotypic changes of the human lumbar plexus roots that are associated with changes in thoracolumbar vertebral counts and trade-offs, that is, a change from thoracic to lumbar vertebrae with no change in the overall thoracolumbar count [23]. Our previous study showed that 1) the concomitant changes in the lumbar nerves and vertebrae were unclear in the typical human (17) or variant (16) thoracolumbar vertebrae, and 2) only a single-segment caudal shift of the lumbar plexus roots tended to be observed in respect to vertebral changes in two segments, with changes ranging from a reduced thoracolumbar count of 16 to an increased count of 18 . Fewer and shorter lumbar vertebrae and more complicated lumbar plexuses in humans are considered some of the causes of the discrepancies seen in experimental embryology. Therefore, we modified the theoretical developmental evidence on the concomitant changes of the lumbosacral plexus roots in experimental animals, whereas those of the human brachial plexus remain unclear.

To date, previous reports in experimental rodents have shown that HOXA-7 regulates the anterior (upper) limit of the brachial plexus and HOXA-9 regulates the posterior (lower) limit [45]. In HOXC-8 mutant mice, the muscle arrangement of the forelimb is normal, but the innervation is perturbed [42]. These experimental evidences suggest that the thoracolumbar mutants also involve not only craniocaudal shifts of the lumbosacral plexus roots, but also brachial plexus shifts. In thoracolumbar mutants that emerge as a result of HOXA-7, -8 , and -9 mutations, which intensely regulate the upper, middle, and lower thoracic vertebrae, the brachial plexuses in these mutants may exhibit additional or reduced main components.

Recently, a meta-analysis study of the human brachial plexus anatomy has revealed many morphological characteristics $[6,7]$. In this analysis, ultimately rare variations in the partial contribution from the third spinal nerve (C3) or almost all contribution from the fourth (C4) or tenth (T2) spinal nerve to the human brachial plexus reported in past studies remain lost information on their vertebral formula. Unfortunately, these past reports generally do not provide information on vertebral formula and therefore cannot verify the phenotypic morphology of the vertebrae and spinal nerves, which should show concomitant changes theoretically. Based on the developmental evidences of the concomitant regulation of thoracolumbar vertebrae and limb plexuses, we hypothesized that many rare cases of additional/ reduced segments of the brachial plexus may include many thoracolumbar mutants.

On the other hand, the cranial and caudal limits of the human brachial plexus are typically very small contributions, and so it is also a fact that it is difficult to accurately evaluate the craniocaudal shift of the brachial plexus roots. The relative position of the axillary artery itself and its branches to the brachial plexus has alternatively examined to obtain a developmental perspective of the human brachial plexus, axillary artery, and their interactions $[11,20$, $21,26,29]$. These conventional anatomical studies expected a stable relationship between the brachial 
plexus and arterial branches in the presence of positional information. Here, we also evaluated the origin, course, and relative position of the axillary artery and its arterial branches relative to the brachial plexus in order to comprehensively evaluate the changes in the brachial plexus.

The main aim of the present study was 1) to clarify whether concomitant developmental changes in human thoracolumbar vertebrae and brachial plexuses are present, 2) to provide data whether the axillary artery penetration point and its branches relative to the brachial plexus are a suitable estimation for the craniocaudal shift of the human brachial plexus, and 3) to determine the phenotypic changes in human brachial plexus roots that are associated with changes in thoracolumbar counts and trade-offs.

\section{MATERIALS AND METHODS}

\section{Examined samples}

The 177 human donated cadavers were first examined to confirm their vertebral formulae and counts. All donors and their families provided consent to donate the bodies to the Toho University School of Medicine for anatomical education and research purposes. The procedure and research protocol for this study was reviewed and approved by the ethics committee at the Toho University Faculty of Medicine (reference number: A20001_A18015_A17033_ A17005_25113_23011). All cadavers were fixed by arterial perfusion with a $7 \%$ formalin solution via the radial or femoral artery and preserved in $10 \%$ alcohol for more than 4 months.

For 79 cadavers, the vertebral formulae were estimated at the time of thoracotomy and laparotomy, and the exact vertebral counts of the cases with a high possibility of vertebral mutations were determined. The other 98 cadavers were subjected to computed tomography (CT) imaging before dissection and then their vertebral formulae were determined.

In this observation, the brachial plexuses in 52 sides of 26 randomly selected cadavers exhibited a typical human vertebral formula (seven cervical, 7C; twelve thoracic, $12 \mathrm{~T}$; five lumbar, $5 \mathrm{~L}$; five sacral, 5S) were compared with those in 20 sides of 10 thoracolumbar mutants out of the 354 sides of the 177 human cadavers.

\section{CT imaging protocols and analysis}

In order to easily confirm the vertebral formulae and to establish the three-dimensional topography of the spine, 98 recent cadavers were subjected to postmortem CT imaging analyses using a Somatom Emotion 16 scanner (Siemens Healthcare GmbH, Erlangen, Germany). We selected the following CT protocols that represent routine protocols for autopsy imaging in our department: a tube voltage of 110 or $130 \mathrm{KV}$, a current of $80-140 \mathrm{~mA}$, a slice width of $0.75 \mathrm{~mm}$, and a reconstruction width of $0.6 \mathrm{~mm}$. Axial DICOM images were reconstructed using commercial software (ZioCube ver. 1.0.0.4; Ziosoft Inc., Tokyo, Japan).

\section{Dissection}

After checking the vertebral count, a detailed physical dissection of the brachial plexus was performed on cases with different thoracolumbar counts, including in cases where changes in thoracolumbar count and trade-offs were highly possible and unconfirmed on CT. We focused on the anatomy of the origin, course, and distribution of the brachial plexus itself, and its relationship with the axially artery and its branches. The findings were recorded with detailed anatomical sketches and/or a digital camera (IXY digital 620F; Canon, Tokyo, Japan). All procedures were also confirmed with the provisions of the 1995 Declaration of Helsinki (revised in Edinburgh in 2000).

\section{Definitions of vertebra and spinal nerves}

The criteria for each vertebral identification were based on previous studies $[4,23,25]$. The brief criterion was as follows: the cervical spines were vertebrae located between the occipital bone and the first vertebra with large bilateral ribs, and they typically have a pair of costal facet on the transverse process in humans. Articulated ribs or rib fossa on both the vertebral body and transverse process of the thoracic vertebrae differentiates these from lumbar vertebrae. The sacral vertebra was defined as the vertebra below the sacroiliac joint and its count was based on its shape and intervertebral line number. The coccygeal vertebrae were excluded from our criteria for normal or abnormal vertebral formulae due to unclear calcification conditions, which make accurate assessments difficult.

The composition of the brachial plexus was mainly composed of segments in which almost all of the nerve components participated in the brachial plexus roots. Those with a small branch were defined as sub-components. In the distal axillary region, the intercostobrachial nerves derived from the second and third thoracic nerves always communicate with 
the medial cutaneous antebrachial (Cabm) and/or brachial (Cbm) nerve, but their peripheral communication did not include the compositional segments of the brachial plexus root. Based on its definition, when the brachial plexus is composed of almost all of the components from the fifth cervical nerves to the first thoracic nerves, the segment is described as C(4)5-T1.

In terms of spinal nerve counts, referring to the "cervical" and "thoracic" nerves can lead to confusion when considering vertebral trade-offs or mutation cases. For this reason, the serial vertebral number was used for the first spinal nerve from the first cervical nerve.

\section{RESULTS}

\section{Vertebral formulae and counts}

In the 177 cadavers examined, the cervical and sacral vertebrae were consistently composed of $7(177 / 177$ sides, 100\%) and 5 vertebrae (173/177, $97.7 \%)$, respectively. Four (2.3\%) cadavers had six sacral vertebrae, which were likely a result of sacralisation from the fifth lumbar to the first sacral vertebra (7C_12T_4 L_6S).

In the 173 cadavers that consistently had seven cervical and five sacral vertebrae $(173 / 177,97.7 \%)$, different thoracolumbar counts were observed, with 5 cadavers having a thoracolumbar count of $16(5 / 173$, $2.9 \%$, Fig. 1A), 166 with the typical 17 (166/173, $96.0 \%$, Fig. 1B), and 2 with 18 (2/173, 1.2\%; Fig. 1C).

Furthermore, in those with a typical thoracolumbar count of 17, a thoracolumbar trade-off with the vertebral formula "7C_11T_6L_5S" was found in three cadavers (3/173, 1.7\%; Fig. 1D).

For those with a mutant thoracolumbar count, four cadavers had a reduced thoracolumbar vertebra count of 16, which included the formula "11T_ 5 L" on six sides and "12T_4 L" on two sides, whereas both cadavers with the mutant thoracolumbar vertebrae count of 18 had a "13T_5 L" formula.

\section{Morphology of the brachial plexus and its artery in a typical human vertebral formula}

For comparison with thoracolumbar mutants, the brachial plexus and its arterial interactions were investigated in randomly selected 52 sides of 26 cases exhibited a typical human vertebral formula (7C_12T_5L_5S) and summarized in Table 1. Because of the importance to distinguish whether almost all or a small communication of nerve root participate in the brachial plexus, the segments that contribute in the brachial plexus only in a small amount such as $4^{\text {th }}$ (Fig. 2A) and $10^{\text {th }}$ (Fig. 2B) spinal nerves were shown in parentheses. Furthermore, the peripheral communication between the intercostobrachal nerves and the medial cutaneous brachial/antebrachial nerve was excluded from the components of the brachial plexus roots (Fig. 2C, D). Consequently, the brachial plexus roots were found in four types, even in typical human vertebral formula (Figs. $2 \mathrm{E}-\mathrm{H}$ ).

Regarding the brachial plexus course, components of the lateral and medial cords were also recognized in three types (Figs. 3A-C). Additionally, multiple communications between the lateral and medial cords (median ansa) (Fig. 3D) and excessive communication between the musculocutaneous and median nerves (Fig. 3E) were also observed.

The relationship between the axillary artery and brachial plexus was shown in Figure 4. A superficial brachial artery running superficially to the ventral division of the brachial plexus was observed in two sides of 52 sides ( $3.8 \%$, Fig. $4 C, D)$, but otherwise the axillary artery passed/penetrated between the lateral and medial cords and coursed between the ventral and dorsal divisions of the brachial plexus (Fig. 4A, B). This penetrating point/root segments of the axillary artery to the brachial plexus corresponded to the root segments of the lateral and medial cords of the brachial plexus. We also investigated the interaction between the axially artery branches and the brachial plexus. The typical branching pattern as seen in anatomical textbooks, which the axially artery issues the superior thoracic, thoracoacromial, and lateral thoracic arteries superficially before the penetration of the brachial plexus whereas the it issues the subscapular artery composing of the thoracodorsal and circumflex scapular arteries and anterior and posterior circumflex arteries deeply after the penetration, was found in 24 of 52 cases $(46.2 \%$, Fig. 4A, B). Other branching patterns were observed mainly focusing on the branching site of the lateral thoracic artery relative to the brachial plexus (Fig. 4E, Table 2).

\section{Morphology of the brachial plexus roots and its axillary artery courses in different thoracolumbar counts and trade-offs}

The individual findings on the vertebral formulae, brachial plexus roots, penetrating points of the axial artery to the brachial plexus, and arterial branches in thoracolumbar mutants are shown in Table 2. The representative brachial plexus and axillary artery diagram- 


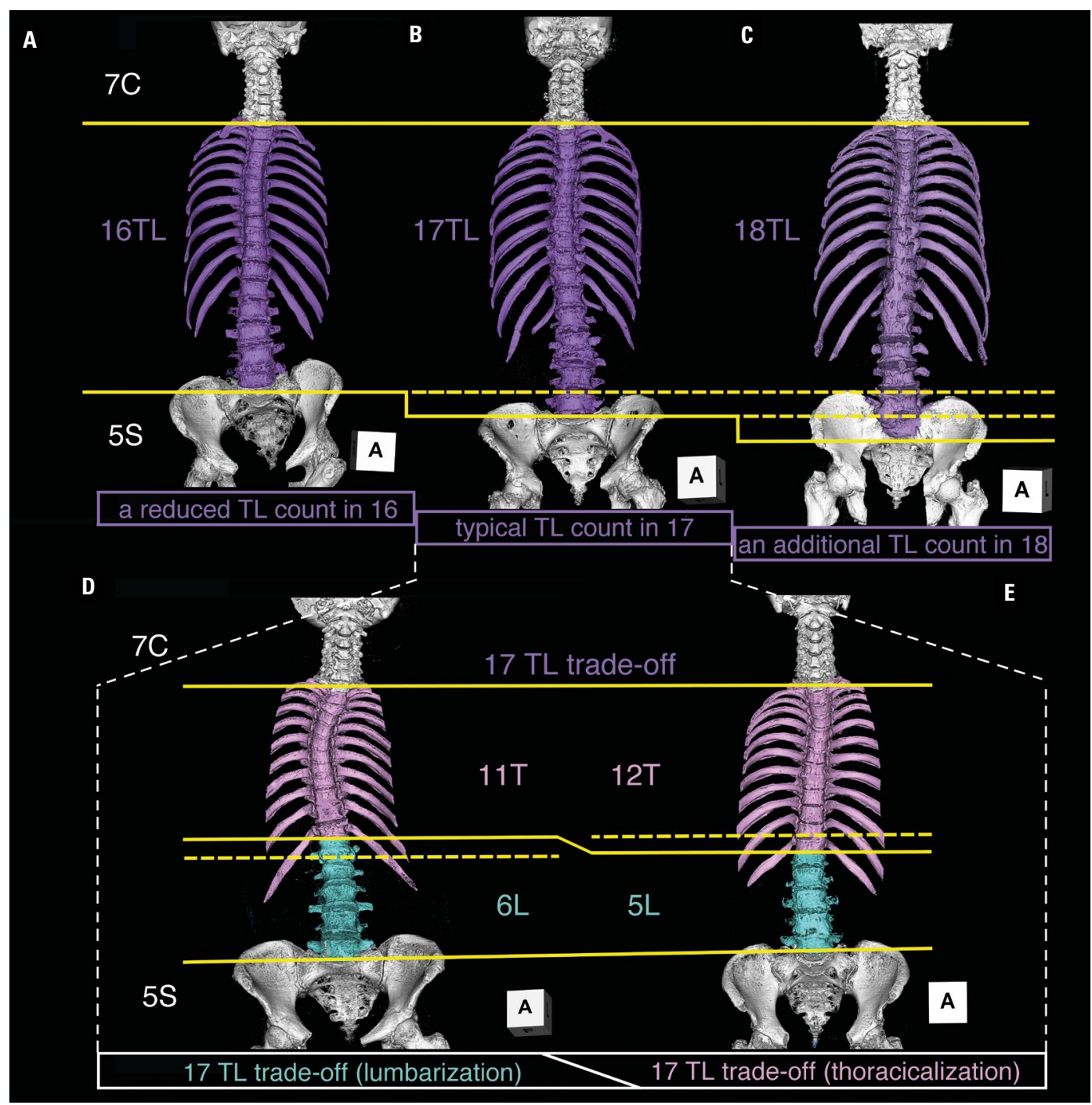

Figure 1. Various human thoracolumbar counts (A-C) and trade-offs (D-E); A. A reduced thoracolumbar count of 16 (7C 16TL 5S); B. A typical thoracolumbar count of 17 (7C_17TL_5S); C. An additional thoracolumbar count of 18 (7C_18TL_5S). The lower panel shows a thoracolumbar trade-off with 17 vertebrae, i.e., a change in vertebrae from thoracic to lumbar with no change in the overall thoracolumbar count; D. Lumbarisation, a thoracic to lumbar trade-off (7C_11T_6L_5S); E. Thoracicalisation, a lumbar to thoracic vertebra trade-off (7C_12T_5L_5S); $\mathrm{ACH}$ - anterior circumflex artery; $\mathrm{AxN}$ - axillary nerve; $\mathrm{BB}$ - branch to biceps brachii muscle; $\mathrm{Br}$ - branch to brachialis muscle; $\bar{B} R \bar{A}$ - brachioradial artery; Cabm — medial cutaneous antebrachial nerve; $\mathrm{CB}$ - branch to the coracobrachialis; $\mathrm{Cbm}$ - medial cutaneous brachial nerve; CS — circumflex scapular artery; DSN — dorsal scapular nerve; I-T — inferior trunk; LC — lateral cord; LT — lateral thoracic artery; LTN — long thoracic nerve; MC — medial cord; MCN — musculocutaneous nerve; MN — median nerve; M-T — middle trunk; $\mathrm{PCH}$ - posterior circumflex artery; $\mathrm{Ph}$ — phrenic nerve; $\mathrm{Pi}$ — inferior pectoral artery; $\mathrm{PN}$ — pectoral nerve; Rcl-10 and11 — lateral cutaneous branch of intercostal nerve of tenth-eleventh spinal nerves; RN — radial nerve; SBA — superficial brachial artery; SCN — subclavian nerve; StG — stellate (cervicothoracic) ganglion; SSN — suprascapular nerve; ST — superior thoracic artery; SuA — subscapular artery; SuCl — supraclavicular nerve; SuN — subscapular nerve; S-T — superior trunk; TA — thoracoacromial artery; TD — thoracodorsal artery; TDN — thoracodorsal nerve; UN — ulnar nerve; 3-11SN — third-eleventh spinal nerves; 2-3TG — second-third thoracic ganglion.

matic findings are presented in Figures 5-7, consisting of 17 thoracolumbar trade-offs (7C_11T_6L_5S, Fig. 5), 16 thoracolumbar counts (7C_11T_5L_5S, Fig. 6), and 18 thoracolumbar counts (7C_13T_5L_5S, Fig. 7). Our results showed that changes in the brachial plexus roots and the axillary artery courses were not specifically associated with changes in thoracolumbar counts and trade-offs (Table 2, Fig. 8).
As overall characteristics on the brachial plexus in different thoracolumbar counts and trade-offs, all of the main components of the brachial plexus roots were composed of five segments and almost all of the components of the $5^{\text {th }}-9^{\text {th }}$ spinal nerves $(20 / 20$ sides, $100.0 \%)$. An additional small contribution was also found in the $4^{\text {th }}$ spinal nerves (17/20 sides, $\left.85.0 \%\right)$ and in the $10^{\text {th }}$ spinal nerves ( $5 / 20$ sides, $25.0 \%$ ). 
Table 1. Variations of the brachial plexus and their arterial system in a typical human vertebral formula (7C_12T_5L_5S)

\begin{tabular}{|c|c|}
\hline \multicolumn{2}{|l|}{ Brachial plexus roots } \\
\hline (4)5-9 $9^{\text {th }}$ spinal nerves (Fig. 2E) & $26 / 52$ sides $(50.0 \%)$ \\
\hline$(4) 5-9(10)^{\text {th }}$ spinal nerves (Fig. 2F) & $4 / 52$ sides $(7.7 \%)$ \\
\hline 5-9 $9^{\text {th }}$ spinal nerves (Fig. 2G) & $18 / 52(34.6 \%)$ \\
\hline 5-9(10) $)^{\text {th }}$ spinal nerves (Fig. 2H) & 4/52 sides $(7.7 \%)$ \\
\hline \multicolumn{2}{|l|}{$\begin{array}{l}\text { Brachial plexus course and communications: } \\
\text { lateral and medial cords }\end{array}$} \\
\hline $\mathrm{LC}<(4) 5-6 \mathrm{SN}>\& \mathrm{MC}<7-9(10) \mathrm{SN}>$ (Fig. 3A) & 2/52 sides $(3.8 \%)$ \\
\hline $\mathrm{LC}<(4) 5-7 \mathrm{SN}>\& \mathrm{MC}<(8-9(10) \mathrm{SN}>$ (Fig. 3B) & $48 / 52$ sides (92.3\%) \\
\hline $\mathrm{LC}<(4) 5-8 \mathrm{SN}>\& \mathrm{MC}<8-9(10) \mathrm{SN}>$ (Fig. 3C) & 2/52 sides (3.8\%) \\
\hline Multiple median ansa (Fig. 3D) & $7 / 52$ sides $(13.5 \%)$ \\
\hline MCN-MN communication (Fig. 3E) & 4/52 sides $(7.7 \%)$ \\
\hline \multicolumn{2}{|l|}{ Axillary artery penetration to the brachial plexus } \\
\hline Non, superficial brachial artery (Fig. 4C, D) & $2 / 52$ sides $(3.8 \%)$ \\
\hline Between $6-7^{\text {th }}$ spinal nerves (Fig. 3A) & 2/52 sides (3.8\%) \\
\hline Between 7-8 $8^{\text {th }}$ spinal nerves (Fig. 3B) & $46 / 52$ sides ( $88.5 \%)$ \\
\hline Between 8-8 $8^{\text {th }}$ spinal nerves (Fig. 3C) & 2/52 sides (3.8\%) \\
\hline \multicolumn{2}{|l|}{ Axillary branches } \\
\hline $\begin{array}{l}\text { Branching pattern in superficial brachial artery } \\
\text { (Fig. 4E-1) }\end{array}$ & $2 / 52$ sides $(3.8 \%)$ \\
\hline Superficial subscapular artery (Fig. 4E-2) & $11 / 52$ sides (21.2\%) \\
\hline $\begin{array}{l}\text { Superficial common trunk of } \mathrm{LT} \text { and TD } \\
\text { with a deep single CS (Fig. 4E-3) }\end{array}$ & $1 / 52$ side $(1.9 \%)$ \\
\hline $\begin{array}{l}\text { Textbook type: superficial LT and deep SuA } \\
\text { composing of TD and CS (Fig. 4E-4) }\end{array}$ & $24 / 52$ sides (46.2\%) \\
\hline Superficial and deep LTs (Fig. 4E-5) & 12/52 sides (23.1\%) \\
\hline Deep common trunk of LT and SuA (Fig. 4E-6) & 2/52 sides $(3.8 \%)$ \\
\hline
\end{tabular}

Therefore, these results showed neither a shift of the brachial plexus nor a change in the count of the brachial plexus roots, such as an additional six segments or four fewer segments.

In 18 of the 20 different thoracolumbar counts and trade-offs (90.0\%), the main trunk of the axillary artery penetrated between the $7^{\text {th }}$ and $8^{\text {th }}$ spinal nerves (C7-8) at the two roots of the median nerve (median ansa), and then coursed between the ventral (anterior) and dorsal (posterior) divisions of the brachial plexus (Figs. 5, 6). The remaining two sides showed different penetrating points of the brachial plexus: one penetrated at C8-T1 due to different components of the medial cord, and was composed of only T1 (1/20 sides, 5.0\%; Fig. 7A). The other coursed outside of the brachial plexus due to the presence of a single ventral cord (so called Adachi's C type) with an absent median ansa (1/20 sides, 5.0\%; Fig. 7B, C). Both penetrating point anomalies were found on the left side of those with the 18-thoracolumbar counts.

Topographical arterial branching patterns of the axillary artery with the brachial plexus in different thoracolumbar counts and trade-offs

Various arterial branching patterns of the axillary artery were also found and differed from the descriptive arterial branching pattern typically shown in textbooks (Fig. 4A, B); the superior thoracic artery (ST) visible in the first part, the thoracoacromial (TA) and lateral thoracic artery (LT) can be seen in the second part, and the subscapular artery (SuA), composed of the thoracodorsal (TD) and circumflex scapular (CS), anterior circumflex humeral $(\mathrm{ACH})$, and posterior circumflex humeral $(\mathrm{PCH})$, can be seen in the third part. However, this separated arterial branching pattern was observed on only three sides $(15.0 \%$, as shown in Fig. $4 \mathrm{E}_{4}$ ). The adjacent arterial branches often formed a common trunk with the ST and TA on two sides, and the TA and LT on three sides (Fig. 5A). In particular, there were many variations related to the branching position of the LT with respect to the two roots of the median nerve (median ansa) as shown in Figures 6, 8. These types were shown as a series of gradual changes from superficial to deeper branching patterns as shown in Figure 8 and completely same variation pattern in normal 17 thoracolumbar vertebra shown in Figure 4E.

\section{DISCUSSION}

The axillary artery and its arterial branches as positional information for brachial plexus classification

Hox genes are known to regulate thoracolumbar counts and formulae; however, other environmental effects such as positional information may also need to be considered [40,44]. Cells having information about their relative position within a cell population and changing their position based on this also suggests a vertebrate body plan. In order to assess subtle changes in cranio-caudal shifts of the human brachial plexus, or to analyse arterial variations in the axillary artery around the brachial plexus, the positional relationship between the axillary artery itself, its arterial branches, and the brachial plexus has been investigated in detail $[1,2,11,20,21,26,28,29,38,47,48]$. In general, the main trunk of the human axillary artery passes through 


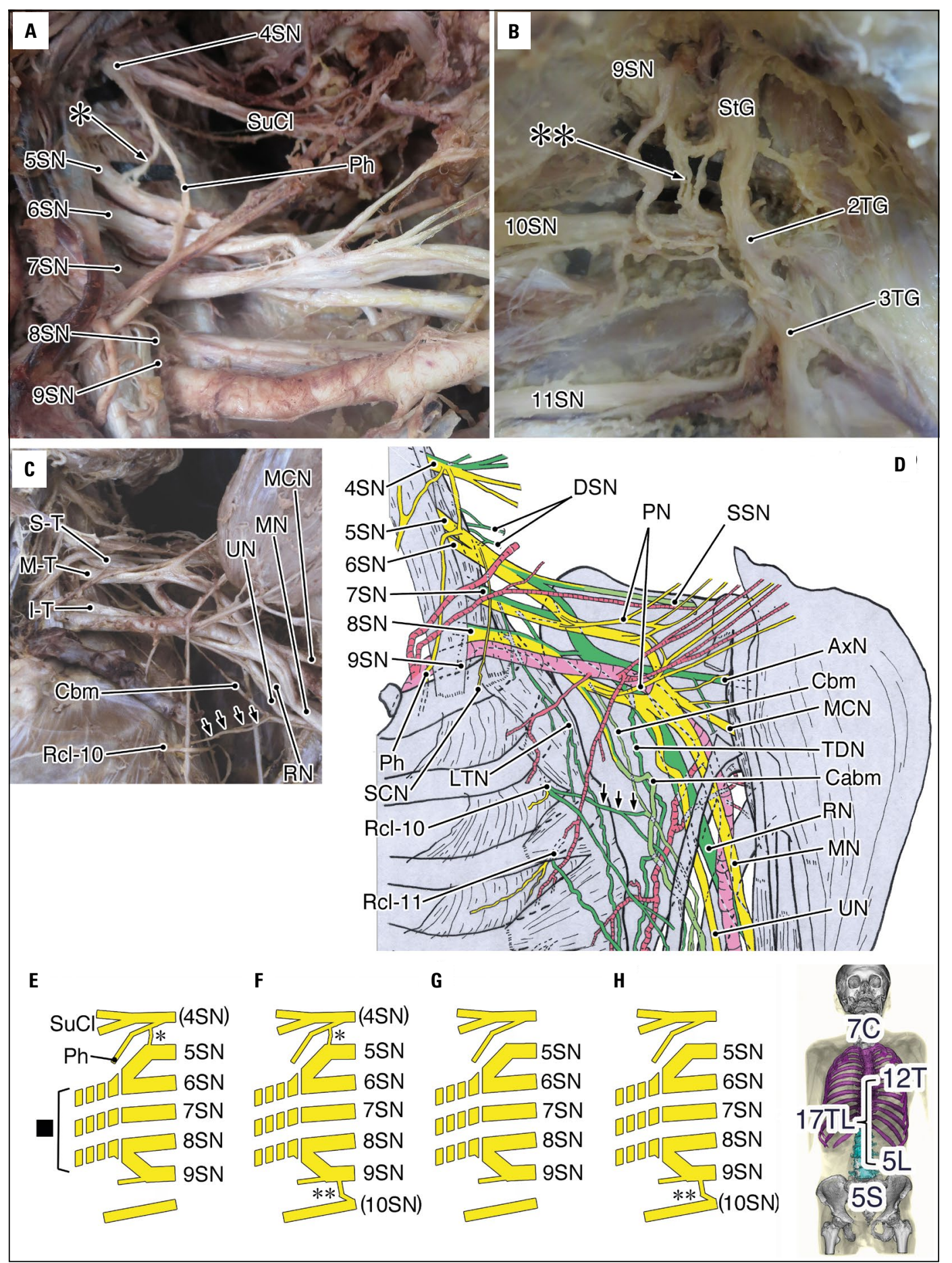

Figure 2. The brachial plexus roots and its variation in a typical human vertebral formula (7C_12T_5L_5S); $\mathbf{A}$. The communicating branches from the fourth spinal nerve to the fifth spinal nerve via the phrenic nerve indicated by a single asterisk $(A)$ and from the $10^{\text {th }}$ to $9^{\text {th }}$ spinal nerves indicated by a double asterisk (B). The photograph (C) and diagram (D) showing the peripheral communicating branch from the intercostobrachial nerve derived from $10^{\text {th }}$ spinal nerve to the medial cutaneous brachial nerve as showing in arrows; E-H. Variation of the human brachial plexus roots. A closed square shows the main components of the brachial plexus. Abbreviations — see Figure 1.

two roots of the median nerve (median ansa), which is composed of the ventral division of $5^{\text {th }}-7^{\text {th }}$ spinal nerves (C5-7) and the medial cords composed of the ventral division of the $8^{\text {th }}-9^{\text {th }}$ spinal nerves (C8-T1), and courses between the ventral (lateral and medial cords) and dorsal divisions (posterior cord). Therefore, the penetration position of the brachial plexus has been conventionally described as C7-8. Kodama (2000) [28] 


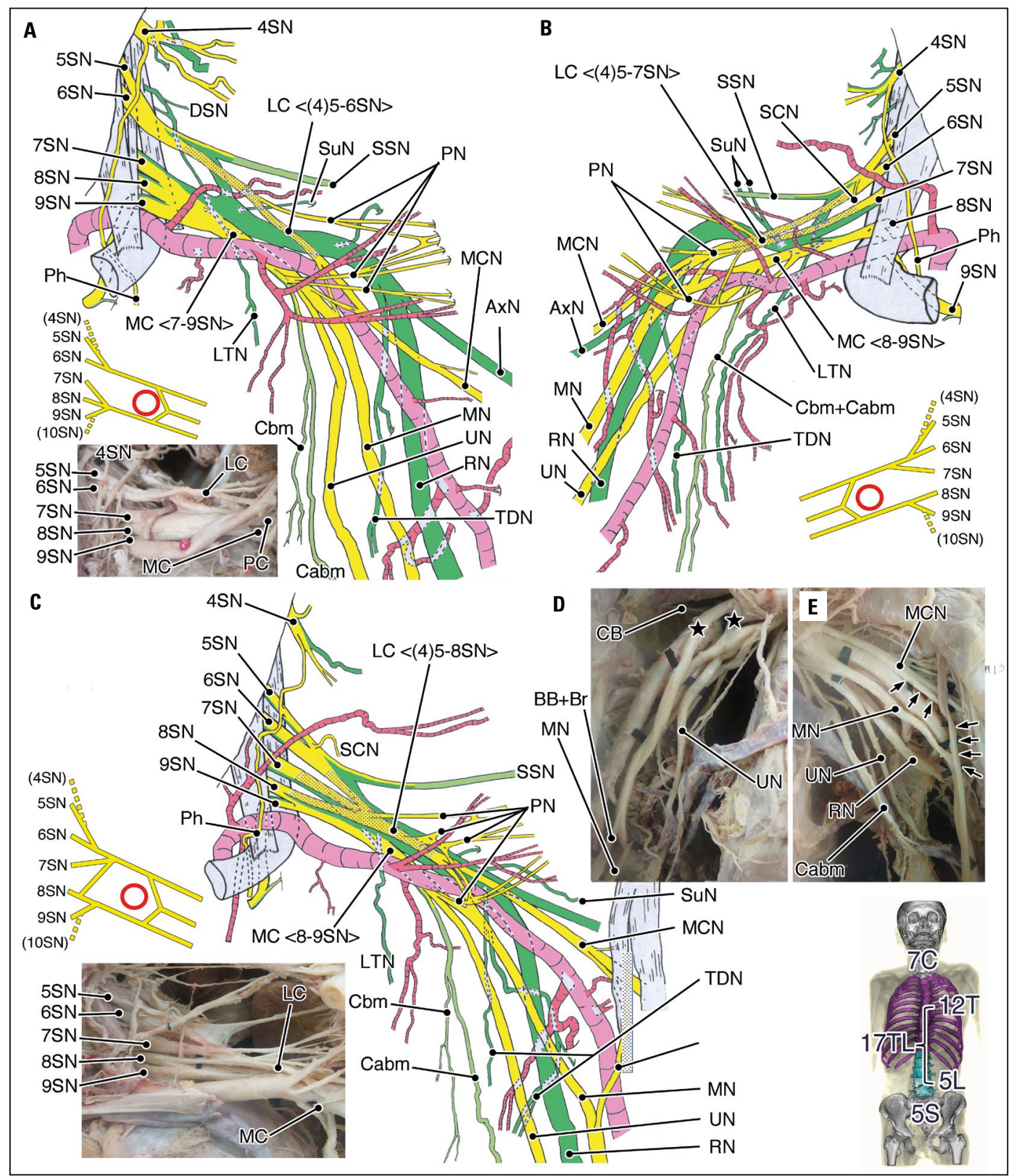

Figure 3. Variation of brachial plexus cords components in course and the interaction with the axillary artery in a typical human vertebral formula (7C_12T_5L_5S); A. The narrow lateral cord $<(4) 5-6^{\text {th }}$ spinal nerves $>$ and wide medial cord $<7-9(10)$ th spinal nerves $>$ segments. The axillary artery penetrates between $6-7^{\text {th }}$ spinal nerves; $\mathbf{B}$. The standard components of the brachial plexus cords and its arterial courses. The lateral and medial cords compose of the $(4) 5-7^{\text {th }}$ and $8-9(10)^{\text {th }}$ spinal nerve, respectively. The axillary artery also penetrates between 7-8 ${ }^{\text {th }}$ spinal nerves; C. The broader lateral and narrower medial cords; D, E. Other variations in the axillary part; $\mathbf{D}$. The multiple medial ansa; E. The musculocutaneous and median nerve communication. Abbreviations - see Figure 1.

investigated the penetration point of the axially artery into normal C7-8 (260/307, 84.7\%), C6-7 (1/307, $0.3 \%), C 7-7(11 / 307,3.6 \%), C 8-8(12 / 307,3.9 \%)$, C8-T1 (3/307, 1.0\%), T1-1 (4/307, 1.3\%), ulnar nerve$-\mathrm{Cbm}(9 / 307,2.9 \%)$, and $\mathrm{T} 1-2(6 / 307,2.0 \%)$ regions. Based on these anatomical data, the left sides from 18 thoracolumbar spines were determined to have a lower penetration of the axial artery, or to have a cranial shift of the brachial plexus. The reasons for these differences are that the axial artery penetrated at C8-T1 in the first case (Fig. 5A), and penetrated at the distal portion of a single ventral cord without making the lateral and medial cords and radial nerve in the second case (Fig. 5B). Due to the small number of occurrences in 18 thoracolumbar spines, it cannot be easily concluded that the frequency is higher than the typical thoracolumbar count of 17 . Rather than thinking that the brachial plexus itself is shift- 

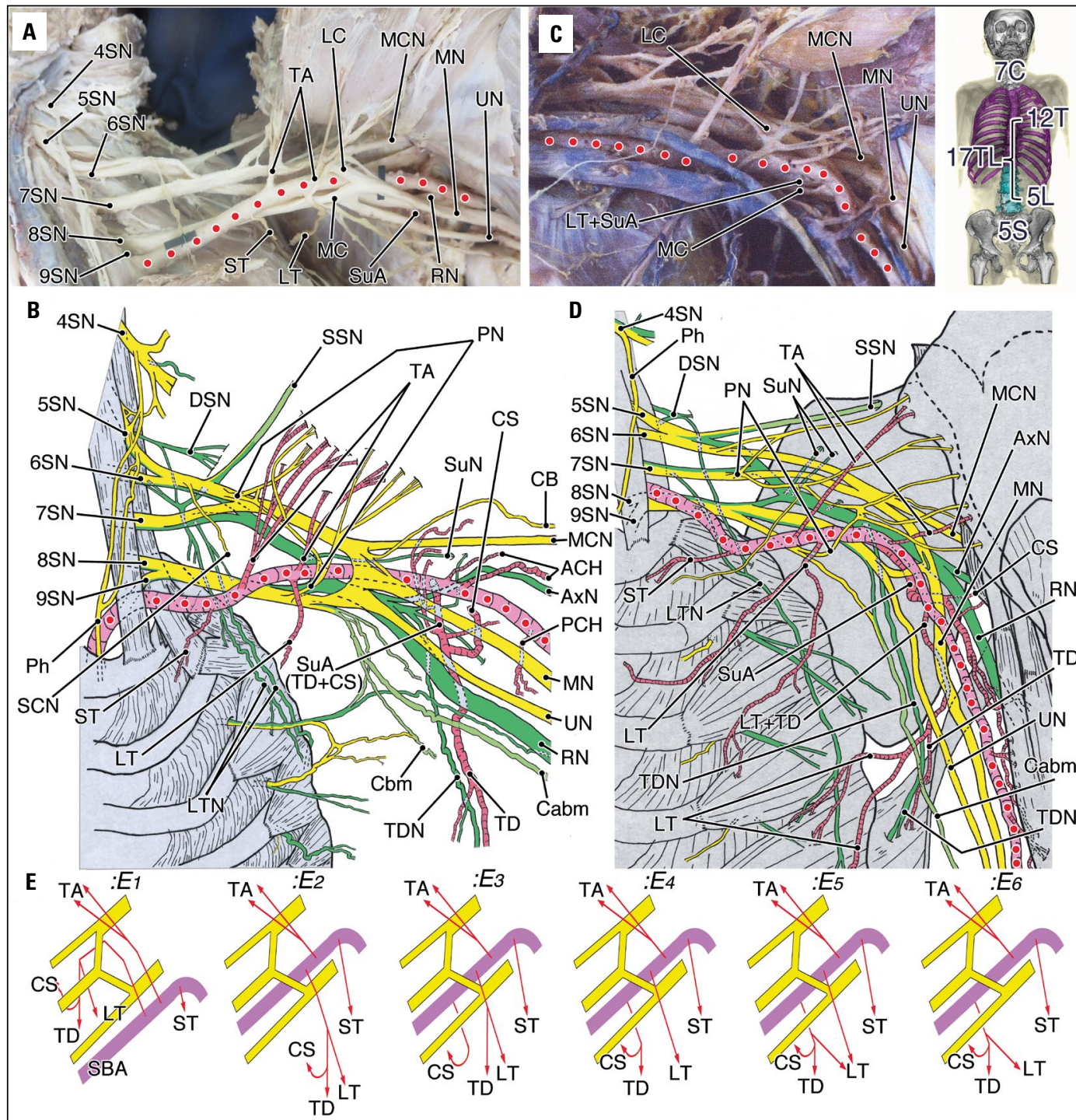

Figure 4. Variation of the axillary artery and its branches in a typical human vertebral formula (7C_12T_5L_5S); A, B. A typical axillary artery course and its branching pattern as seen in anatomical descriptions. The axillary artery penetrates at two roots of the median nerve (median ansa), which composes the lateral and medial cords of the brachial plexus, and then courses between the ventral and dorsal divisions. The ventral and dorsal divisions of the brachial plexus were coloured in yellow and green, respectively. A part of the second and third thoracic nerves communicate with the brachial plexus branches as the intercostobrachial nerves as shown in arrows, but these communications outside of the segmental roots were excluded from the main component of the brachial plexus. The superior thoracic (ST), thoracoacromial (TA), and lateral thoracic (LT) arteries tend to branch separately from the superficial part of the axial artery before penetrating two roots of the median nerve (median ansa), whereas the subscapular (SuA), anterior ( $\mathrm{ACH}$ ), and posterior circumflex (PCH) arteries branch deeper after penetrating two roots of the median nerve (median ansa); C, D. The aberrant superficial brachial artery running superficially to the ventral division of the brachial plexus without the brachial plexus penetration; E. Variation of the arterial branches from the axillary artery. Abbreviations - see Figure 1.

ing cranio-caudally, it these changes may be due to a variation of the axial artery, or an anomalous course of the brachial plexus composition itself.

Variability in the branches of the axially artery has also been reported. The main trunk of the artery that supplies the branches is divided into three parts. In the general anatomical description, the first part of the axial artery issues only the ST; the second part issues the TA and LT at the superficial portion be- fore penetration, and the third part issues the SuA, $\mathrm{CHA}$, and CHP at the deep portion after penetration, respectively $[16,33,41]$. However, it is well reported that adjacent arterial branches make a common trunk according to their morphological significance, obtaining a clue for the respective superficial brachial artery. When the SuA branches from the LT artery and before it penetrates into two roots of the median nerve (median ansa), it is named the superficial 
Table 2. Individual finding on the brachial plexus and axillary artery branches in human thoracolumbar mutants

\begin{tabular}{|c|c|c|c|c|c|c|c|}
\hline ID & Sex & Side & Vertebral formula & Brachial plexus roots & Axillary artery penetration & Arterial branches & Remark \\
\hline \multicolumn{8}{|c|}{17 thoracolumbar trade-off, 6 sides } \\
\hline \multirow[t]{2}{*}{$17-1$} & $\mathrm{~F}$ & $\mathrm{R}$ & 7C_11T_6L_5S & $(4) 5-9(10)^{\text {th }}$ spinal nerves & Between $7-8^{\text {th }}$ spinal nerves & $\mathrm{TA}+\mathrm{LT}$ & \\
\hline & & L & 7C_11T_6L_5S & (4) $5_{-9^{\text {th }}}$ spinal nerves & Between $7-8^{\text {th }}$ spinal nerves & $\mathrm{TA}+\mathrm{LT}$ & Fig. $5 \mathrm{~A}$ \\
\hline \multirow[t]{2}{*}{$17-2$} & $\mathrm{~F}$ & $\mathrm{R}$ & 7C_11T_6L_5S & (4) $5-9^{\text {th }}$ spinal nerves & Between 7-8 $8^{\text {th }}$ spinal nerves (BRA) & Deep LT + SuA & Fig. 5B \\
\hline & & L & 7C_11T_6L_5S & (4) $5-9^{\text {th }}$ spinal nerves & Between $7-8^{\text {th }}$ spinal nerves & Deep LT + SuA & \\
\hline \multirow[t]{2}{*}{$17-3$} & & $\mathrm{R}$ & 7C_11T_6L_5S & $5-9^{\text {th }}$ spinal nerves & Between $7-8^{\text {th }}$ spinal nerves & $\begin{array}{c}S T+T A \text {, superficial and } \\
\text { deep TAs }\end{array}$ & \\
\hline & & $\mathrm{L}$ & 7C_11T_6L_5S & (4) $5-9^{\text {th }}$ spinal nerves & Between $7-8^{\text {th }}$ spinal nerves & Superficial SuA & \\
\hline \multicolumn{8}{|c|}{16 thoracolumbar vertebrae, 10 sides } \\
\hline \multirow[t]{2}{*}{$16-1$} & $\mathrm{~F}$ & $\mathrm{R}$ & 7C_11T_5L_5S & (4)5-9 gth $^{\text {th }}$ spinal nerves & Between $7-8^{\text {th }}$ spinal nerves & $\mathrm{ST}+\mathrm{TA}$ & \\
\hline & & L & 7C_11T_5L_5S & (4)5-9 $9^{\text {th }}$ spinal nerves & Between $7-8^{\text {th }}$ spinal nerves & Superficial and deep LTs & Fig. 6C \\
\hline \multirow[t]{2}{*}{$16-2$} & $\mathrm{~F}$ & $\mathrm{R}$ & 7C_11T_5L_5S & (4)5-9 $-9^{\text {th }}$ spinal nerves & Between $7-8^{\text {th }}$ spinal nerves & $\mathrm{TA}+\mathrm{LT}$ & \\
\hline & & L & 7C_11T_5L_5S & (4)5-9 $9^{\text {th }}$ spinal nerves & Between $7-8^{\text {th }}$ spinal nerves & Superficial SuA & \\
\hline \multirow[t]{2}{*}{$16-3$} & $\mathrm{~F}$ & $\mathrm{R}$ & 7C_12T_4L_5S & (4)5-9 $9^{\text {th }}$ spinal nerves & Between $7-8^{\text {th }}$ spinal nerves & Superficial SuA & \\
\hline & & L & 7C_12T_4L_5S & (4) $5-9^{\text {th }}$ spinal nerves & Between $7-8^{\text {th }}$ spinal nerves & Superficial SuA & Fig. $6 \mathrm{~A}$ \\
\hline \multirow[t]{2}{*}{$16-4$} & $\mathrm{~F}$ & $\mathrm{R}$ & 7C_11T_5L_5S & (4) $5-9^{\text {th }}$ spinal nerves & Between $7-8^{\text {th }}$ spinal nerves & Typical separated a. & \\
\hline & & L & 7C_11T_5L_5S & (4) $5-9^{\text {th }}$ spinal nerves & Between $7-8^{\text {th }}$ spinal nerves & Deep LT + SuA & Fig. $6 \mathrm{D}$ \\
\hline \multirow[t]{2}{*}{$16-5$} & $\mathrm{~F}$ & $\mathrm{R}$ & 7C_11T_5L_5S & (4) $5-(9) 10^{\text {th }}$ spinal nerves & Between $7-8^{\text {th }}$ spinal nerves & Superficial SuA & \\
\hline & & L & 7C_11T_5L_5S & $5-9(10)^{\text {th }}$ spinal nerves & Between $7-8^{\text {th }}$ spinal nerves & $\begin{array}{l}\text { Superficial SuA, } \\
\text { single CS }\end{array}$ & Fig. $6 \mathrm{~B}$ \\
\hline \multicolumn{8}{|c|}{18 thoracolumbar vertebrae, 4 sides } \\
\hline \multirow[t]{2}{*}{$18-1$} & $\mathrm{~F}$ & $\mathrm{R}$ & 7C_13T_5L_5S & (4) 5-9 $9^{\text {th }}$ spinal nerves & Between 7-8 ${ }^{\text {th }}$ spinal nerves & Superficial SuA & \\
\hline & & $\mathrm{L}$ & 7C_13T_5L_5S & (4) $5-9^{\text {th }}$ spinal nerves & Between 8-9 $9^{\text {th }}$ spinal nerves & Deep LT + SuA & Fig. $7 \mathrm{~A}$ \\
\hline \multirow[t]{2}{*}{$18-2$} & $\mathrm{M}$ & $\mathrm{R}$ & 7C_13T_5L_5S & $5-9(10)^{\text {th }}$ spinal nerves & Between $7-8^{\text {th }}$ spinal nerves & Typical separated a. & \\
\hline & & $L$ & 7C_13T_5L_5S & $(4) 5-9(10)^{\text {th }}$ spinal nerves & $\begin{array}{l}\text { Between ventral and dorsal } \\
\text { divisions }\end{array}$ & Typical separated a. & Fig. $7 C$ \\
\hline Total & & & & $4^{\text {th }}$ spinal nerves, $17 / 20$ & $7-8^{\text {th }}$ spinal nerves, $18 / 20$ & $\mathrm{ST}+\mathrm{TA}, 2 / 20$ & \\
\hline \multirow[t]{6}{*}{20 sides } & & & & $5-9^{\text {th }}$ spinal nerves, $20 / 20$ & $8-9^{\text {th }}$ spinal nerves, $1 / 20$ & $\mathrm{TA}+\mathrm{LT}, 3 / 20$ & \\
\hline & & & & $10^{\text {th }}$ spinal nerves, $5 / 20$ & Ventral and dorsal divisions, 1/20 & $\begin{array}{l}\text { Typical separated a., } \\
3 / 20\end{array}$ & \\
\hline & & & & & & $\begin{array}{l}\text { Type 1: Superficial SuA, } \\
\text { 7/20 }\end{array}$ & \\
\hline & & & & & & $\begin{array}{l}\text { Type 2: Superficial SuA, } \\
\text { single CS, } 1 / 20\end{array}$ & \\
\hline & & & & & & $\begin{array}{l}\text { Type 3: Superficial and } \\
\text { deep LTs, 2/20 }\end{array}$ & \\
\hline & & & & & & $\begin{array}{c}\text { Type 4: Deep LT + SuA, } \\
3 / 20\end{array}$ & \\
\hline
\end{tabular}

a — artery; BRA — brachioradial artery; CS — circumflex scapular artery; F — female; L — left; LT — lateral thoracic artery; $\mathrm{M}$ - male; R — right; ST — superior thoracic artery; SuA — subscapular artery; TA — thoracoacromial artery

SuA [47]. Based on these common arterial trunk morphologies and variations, it has been suggested that the superficial brachial artery is from which all of the distal branches from the superficial SuA form a common trunk with the LT. In addition to the LT, it has been proposed that an arterial branch, namely the inferior pectoral artery, which runs along the lower edge of the pectoralis major and is distributed to the mammary gland, acts as a trigger artery for the superficial brachial artery [29]. Our past research also reported various common trunks formed from the arterial branches of the axial artery, as well as their 


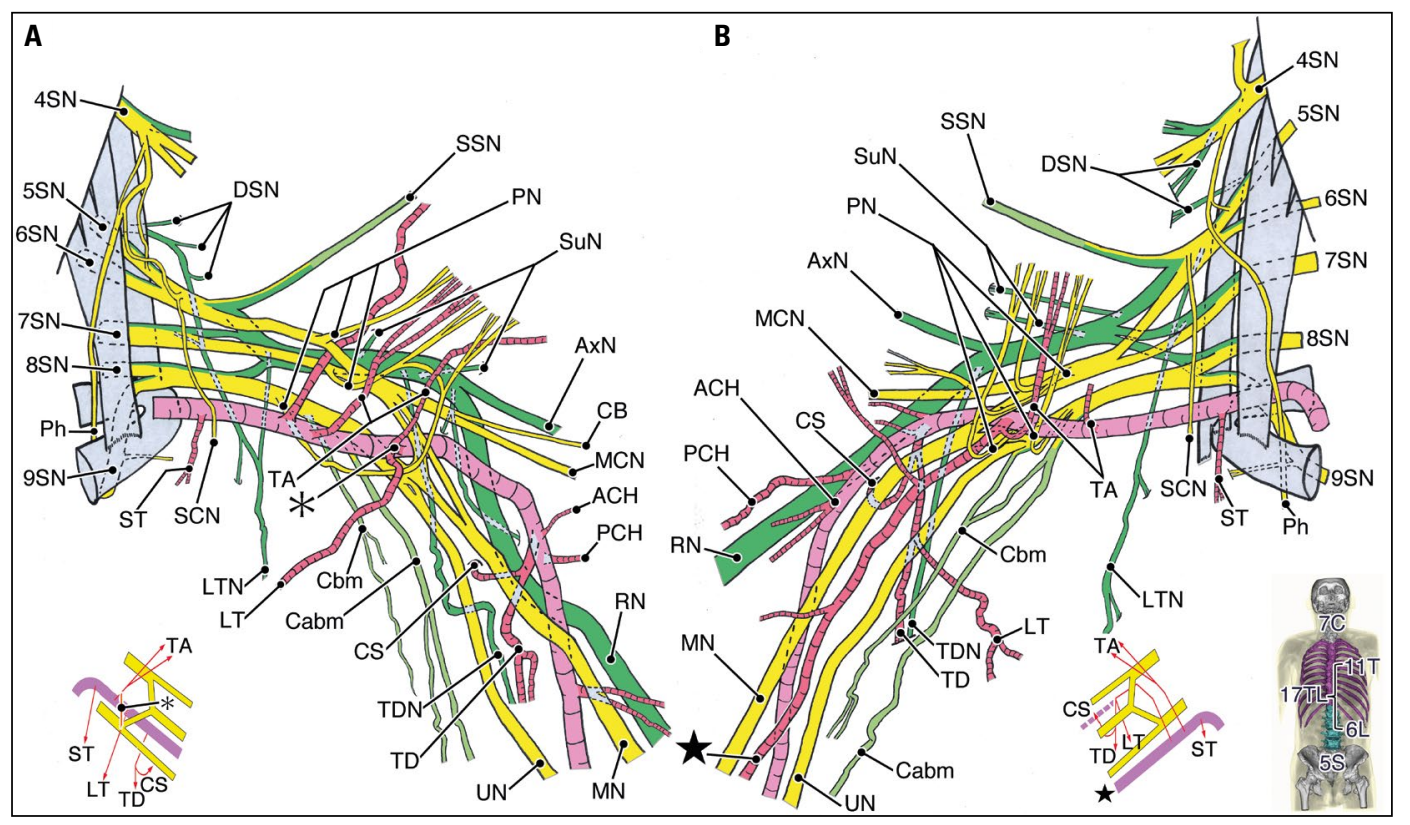

Figure 5. The brachial plexus and variations in the arterial branches of the axial artery in a human thoracolumbar trade-off (17 count); A. A common trunk of one of the thoracoacromial (TA) and lateral thoracic (LT) arteries indicated by an asterisk; B. The higher axillary origin of the brachioradial artery is indicated by a star. Abbreviations - see Figure 1.

topographical relationship with the brachial plexus in the typical human vertebral formulae 7C-17TL-5S [26]. In a Granada report involving 420 sides that focused on the LT, the most common types of branching were where the LT arises from the TA (67.62\%), from the axillary artery as a single branch as described as standard in textbooks (17.02\%), from the TD (3.93\%), and the existence of accessory LT (3.09\%) [32]. On the other hand, Xhakaza and Satyapal (2014) [46] found that LT had a common trunk with the SuA in $33.7 \%$ of 100 sides of Black South Africans, although it is unclear whether they were superficial or deep to two roots of the median nerve (median ansa). These results clearly show a considerable population difference. In the present study, we observed four superficial subscapular arteries (Fig. 6A) in 16 thoracolumbar counts; we also visualised the gradual origins of the arterial branches of the axillary artery, from the superficial to the deep part of the main trunk, as shown in the thoracolumbar mutations with only 16 vertebrae (Fig. 6). We did not find a positive relationship between the changes in the brachial plexus and the arterial system in the thoracolumbar mutants. The present data cannot support the conventional anatomical idea that craniocaudal shifts of the nerve roots can be assessed based on variable arterial correlations, including the penetrating point of the axillary artery into the brachial plexus and the stratigraphic relationship of the arterial branches with the brachial plexus.

\section{Phenotypic changes of the brachial plexus roots in variant thoracolumbar counts}

Unlike variable thoracolumbar counts and formulae, the cervical segment of the vertebral column is strictly fixed as seven vertebrae in almost all mammals, except in sloths and manatees $[4,8,12$, $25,35]$. Furthermore, four of the five main roots of the human brachial plexus are the cervical nerves. Therefore, past studies on the human brachial plexus have naturally neglected to check the relationship between thoracolumbar counts and formulae. On the other hand, detailed anatomical findings on nerve compressions and entrapments of the brachial plexus components have been reported with its association with congenital malformations of their axial skeletons $[3,39]$. These clinical demands and its developmental interactions require more precise anatomical knowledge of the concomitant changes in the axial skeleton and spinal nerves.

In anatomical studies on human brachial plexuses itself, single-corded brachial plexuses (C-type brachial plexus) [19] and their relationship with the superficial brachial artery have been studied [9-11]; however, in these sample series, it is unknown whether they have normal or aberrant thoracolumbar counts and 


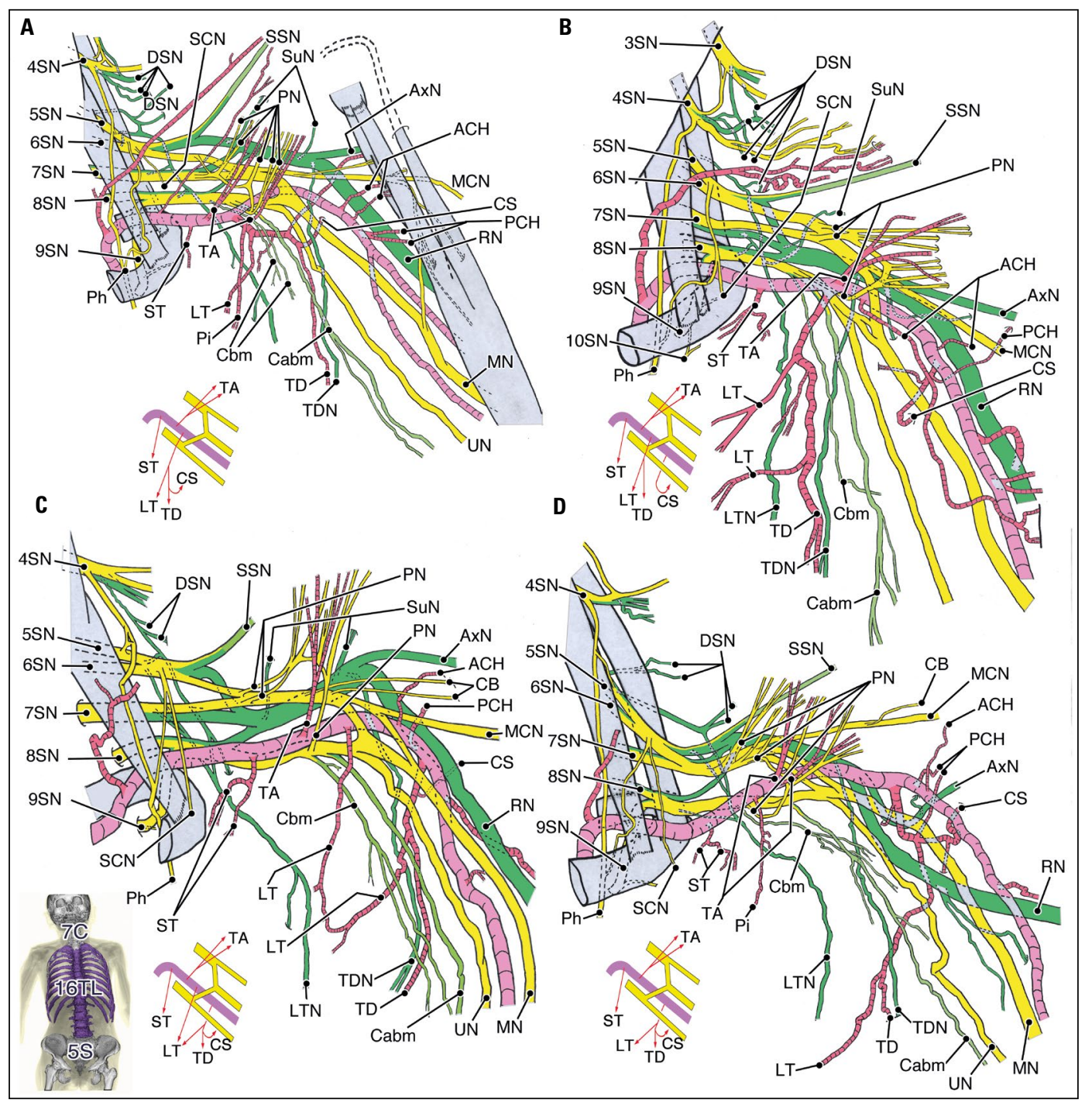

Figure 6. The brachial plexus and the various branching patterns of the axial artery in a thoracolumbar mutant with a count of 16; A. Superficial subscapular artery (Yamada, 1967); B. A common trunk of the lateral thoracic artery (LT) and thoracodorsal artery (TD) branched from the axillary artery before penetrating two roots of the median nerve, but only the circumflex scapular artery (CS) branched after penetrating two roots; C. Multiple LTs coexisted in both the branches before and after penetrating two roots of the median nerve; $\mathbf{D}$. The LT made a common trunk with the subscapular artery and branched from the axillary artery at the deep part or at a third part of the artery. From type 1 to 4 , the branching portion of the lateral thoracic artery emerges from the distal and deep parts of the axillary artery. Abbreviations — see Figure 1.

formulae. Regardless of the thoracolumbar counts in our material series, all main root components of the brachial plexus involved only the $5-9^{\text {th }}$ spinal nerves, with a small contribution by the $4^{\text {th }}(17 / 20,85.0 \%)$ and $10^{\text {th }}$ nerves $(4 / 20,20.0 \%)$. In studies using larger samples with uncertain vertebral formulae, the main human brachial plexus roots are also composed of the $5^{-9^{\text {th }}}$ spinal nerves (C5-T1) $[9,10,26]$. Hirasawa (1931) [19] also identified a small contribution from C3 (1.0\%), C4 (30.0\%), and T2 (16.5\%) to the brachial plexus on 200 sides. This result was similar to ours in terms of the contribution by $\mathrm{T} 2$, but the aforementioned study had less C4 involvement. The phrenic nerve mostly sends a very thin branch to the upper trunk at a point passing through the superficial aspect of the upper trunk; therefore, the fine $\mathrm{C} 4$ branch actually participates in the brachial plexus more frequently (Fig. 1B). On the other hand, cases of $\mathrm{C} 3$ contribution to the human brachial plexus are quite rare and rarely reported $[6,7,19]$, and we have never observed it in our 322 previously studied sides [26], nor in the present 354 sides.

Regarding the structural variation observed in the ramification of the brachial plexus, weak inferior trunks and medial cords composed of only $\mathrm{T} 1$ were reported in 12 out of $716(1.7 \%)$ sides $[10,11]$. This result is similar to the results seen in our first 


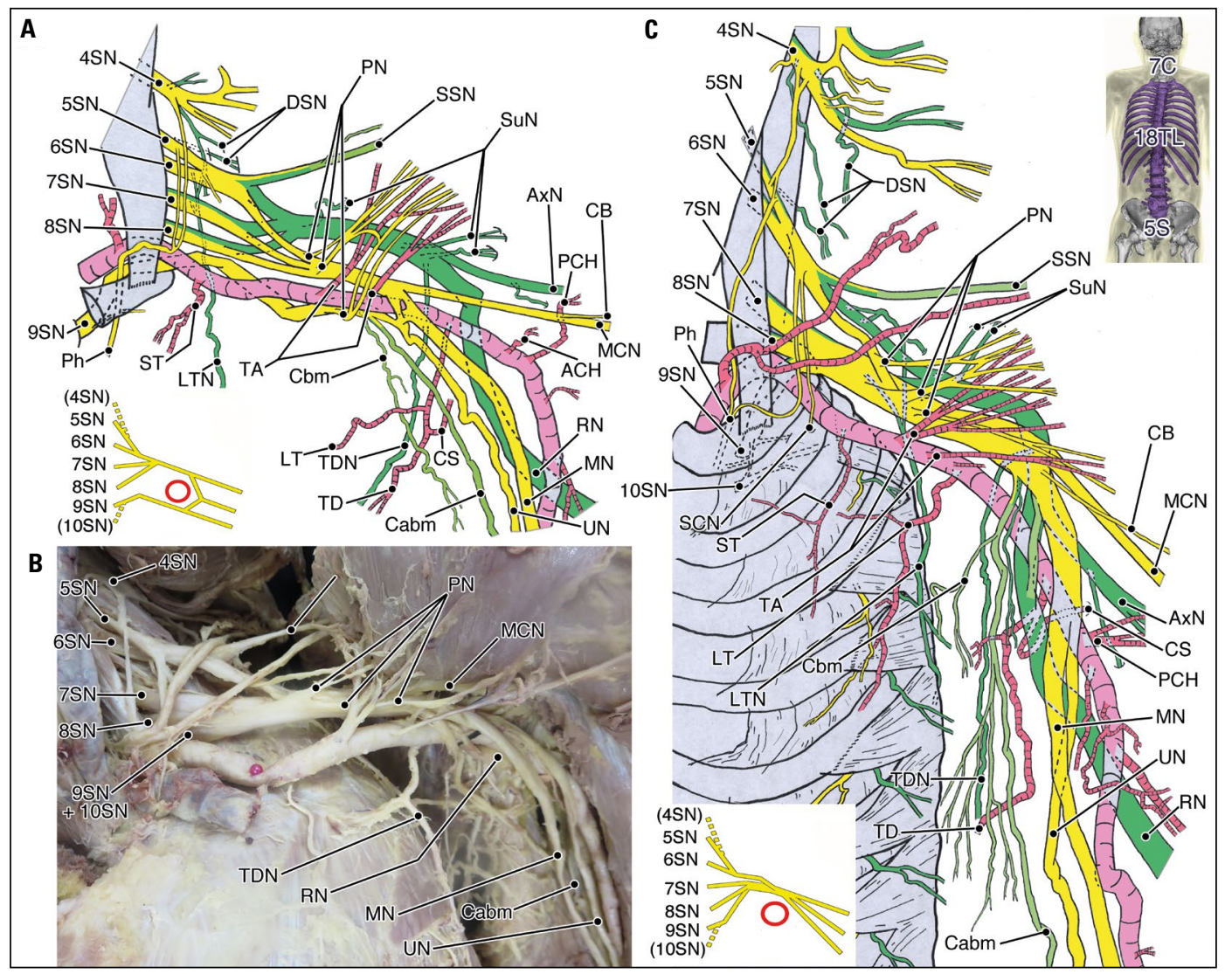

Figure 7. Anomalies of the brachial plexus and axillary artery in a mutant with a thoracolumbar count of 18; $\mathbf{A}$. A weak inferior trunk and medial cord composed of only the $9^{\text {th }}$ spinal nerve (T1), so that the axillary artery penetrates between the $8^{\text {th }}$ and $9^{\text {th }}$ spinal nerves (C8-T1). The photograph (B) and its diagram (C) show the single ventral cord with the absence of two roots of the median nerve (median ansa). Abbreviations - see Figure 1.

thoracolumbar case with 18 vertebrae (Fig. 5A). The aforementioned studies also observed simple-cord brachial plexuses in 26 sides (3.6\%), including a single bundle (C-type brachial plexus). A unique brachial plexus composing of two trunks and one ventral cord was also reported [36], which is similar to our second 18-thoracolumbar-vertebrae case (Fig. 7B, C). The few brachial plexus anomalies seen in previous reports include anomalies in thoracolumbar anomalies, and further examination is needed to determine whether thoracolumbar mutants show a higher percentage of brachial plexus anomalies. In our cases, the main roots of the $5^{\text {th }} 9^{\text {th }}$ nerves were completely stable, and this was the case for both normal and mutant thoracolumbar trade-offs and counts.

These results are different from the lumbosacral plexus, which shows concomitant changes in the thoracolumbar mutations $[5,22,23,35,37]$. The phenotypic morphology of the human brachial plexus is less likely to result in theoretical craniocaudal shifts and thoracolumbar mutations.
Craniocaudal shifts of the cervical and thoracic boundaries were determined to be regulated by HOX6 in sloths and manatees, with exceptionally different cervical counts seen among mammals and birds with extremely large cervical counts $[18,43]$. HOX6 mutants may also show changes in the cranial roots of the brachial plexus. On the other hand, HOX7, which regulates the anterior (cranial) limit of the brachial plexus and the upper thoracic segment of the vertebral column, may have mutants that exhibit additional or reduced components of the brachial plexus roots, such as component contributions involving $\mathrm{T} 2$ and T3 almost exclusively, or reduced contributions of $\mathrm{T} 1$ roots to the brachial plexus. However, no case with a caudal expansion or cranial reduction of the brachial plexus roots was observed in our atypical thoracolumbar counts. In other words, these findings of neither changes in counts nor craniocaudal shifts of the brachial plexus roots lead us to consider that the current thoracolumbar mutations involve only caudal Hox genes such as HOX10, and not HOX7. 


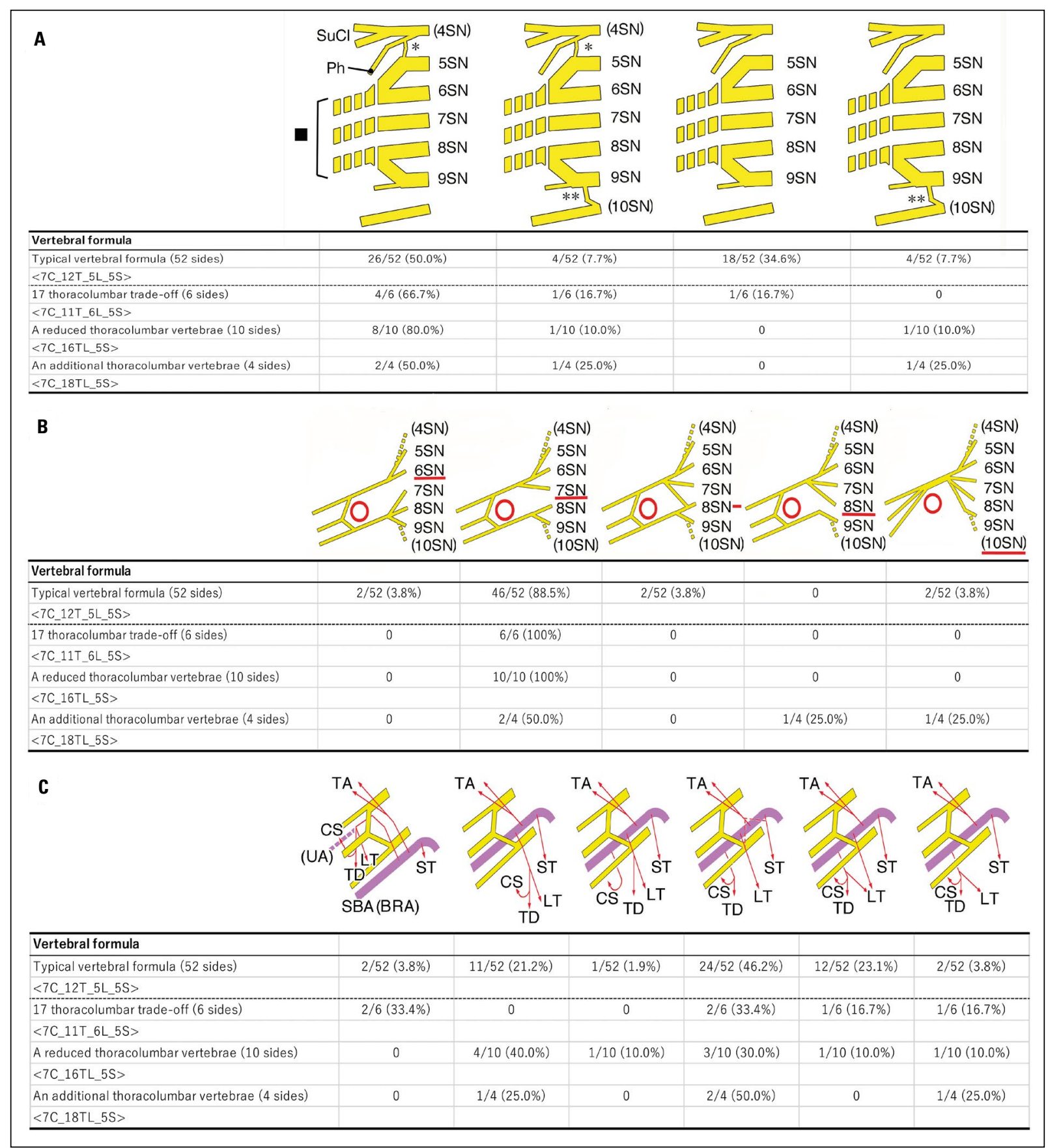

Figure 8. Comparison data on anatomical variability of the human brachial plexus roots and its axillary artery in a typical vertebral formula and different thoracolumbar counts and trade-offs; $\mathbf{A}$. The brachial plexus roots. The communicating branches from the fourth spinal nerve to the fifth spinal nerve via the phrenic nerve indicated by a single asterisk and from the $10^{\text {th }}$ to $9^{\text {th }}$ spinal nerves indicated by a double asterisk.

A closed square shows the main components of the brachial plexus; B. The axillary artery penetration point to the brachial plexus. Red circles show the penetration point of the axillary artery; C. The axillary artery branches. Abbreviations - see Figure 1.

\section{CONCLUSIONS}

Hox genes 7-10, which typically regulate the thoracolumbar segment of the vertebral column, have been shown to also involve HOX7 in the anterior limit of the brachial plexus, express HOX9 in the posterior limit of the brachial plexus, and express
HOX10 in the anterior limit of the lumbosacral plexus. Therefore, different thoracolumbar counts may involve craniocaudal shifts and/or anomalous root counts in segments of the brachial plexus.

In all of our cases of changes in thoracolumbar trade-off and counts, the main components of the 
brachial plexus roots were composed of the $5^{\text {th }}-9^{\text {th }}$ spinal nerves ( $\mathrm{C} 5-\mathrm{T} 1)$, which are the same components as those seen in normal thoracolumbar vertebrae, and this finding was independent of its surrounding arterial patterns. Our present findings suggest that the phenotypic morphology of the human brachial plexus may be less likely to exhibit theoretical concomitant changes in thoracolumbar compositions, and further data is needed for its accuracy.

\section{Acknowledgements}

With the essential fact that anatomical researches have been made possible in the body donation programme [24], the authors sincerely acknowledge the individuals who donated their bodies to Toho University for our education and research. The authors also thank all the members of our department for their valuable help, encouragement, and discussion of our results. This work was supported by the Japan Society for the Promotion of Sciences (JSPS) (Grants-in-Aid for Scientific Research (C), grant numbers: 16K10640, 19K09278).

\section{Conflict of interest: None declared}

\section{REFERENCES}

1. Aizawa $Y$, Ohtsuka K, Kumaki K. [Examination on the courses of the arteries in the axillary region $I$. The course of the subscapular artery system, especially the relationships between the arteries and the posterior cord of the brachial plexus]. Acta Anat Nippon. 1995; 70(6): 554-568, indexed in Pubmed: 8721810.

2. Aizawa Y, Ohtsuka K, Kumaki K. [Examination of the courses of the arteries in the axillary region. II. The course of the axillary artery in the case of Adachi's C-type brachial plexus]. Acta Anat Nippon. 1996; 71(2): 92-105, indexed in Pubmed: 8741278.

3. Artico M, Santarelli MT, Stevanato G, et al. The role of congenital malformations of the thoracic outlet in the development of the syndrome. Folia Morphol. 2022; 81(1): 117-123, doi: 10.5603/FM.a2020.0152, indexed in Pubmed: 33438186.

4. Asher RJ, Lin $\mathrm{KH}$, Kardjilov $\mathrm{N}$, et al. Variability and constraint in the mammalian vertebral column. J Evol Biol. 2011; 24(5): 1080-1090, doi: 10.1111/j.14209101.2011.02240.x, indexed in Pubmed: 21338435.

5. Bardeen C. A statistical study of the abdominal and border nerves in man. Am J Anat. 1902; 1(2): 203-228, doi: 10.1002/aja.1000010206.

6. Benes M, Kachlik D, Belbl M, et al. A meta-analysis on the anatomical variability of the brachial plexus: Part I: Roots, trunks, divisions and cords. Ann Anat. 2021; 238: 151751, doi: 10.1016/j.aanat.2021.151751, indexed in Pubmed: 33940116.

7. Benes $M$, Kachlik D, Belbl M, et al. A meta-analysis on the anatomical variability of the brachial plexus: Part II:
Branching of the supraclavicular part. Ann Anat. 2021; 238: 151788, doi: 10.1016/j.aanat.2021.151788, indexed in Pubmed: 34186202.

8. Böhmer C, Amson E, Arnold P, et al. Homeotic transformations reflect departure from the mammalian 'rule of seven' cervical vertebrae in sloths: inferences on the Hox code and morphological modularity of the mammalian neck. BMC Evol Biol. 2018; 18(1): 84, doi: 10.1186/s12862018-1202-5, indexed in Pubmed: 29879896.

9. Carroll MA, Blandino J, Flynn A, et al. Neurovascular axillary variations: superficial brachial artery and single-corded brachial plexus. Anat Sci Int. 2021; 96(1): 161-167, doi: 10.1007/s12565-020-00563-x, indexed in Pubmed: 32785843.

10. Chiba S. [Morphological studies of the so-called Adachi's C-type brachial plexus. 2. Fasciculation of the plexus and segmental constitution of the nerves]. Acta Anat Nippon. 1984; 59(6): 707-722, indexed in Pubmed: 6535362.

11. Chiba S. Morphological study of the so-called Adachi's C-type brachial plexus. 3. Course of the axillary artery in relation to the brachial plexus. Acta Anat Nippon. 1986; 61: 9-28.

12. Galis F, Van Dooren TJM, Feuth JD, et al. Extreme selection in humans against homeotic transformations of cervical vertebrae. Evolution. 2006; 60(12): 2643-2654, indexed in Pubmed: 17263123.

13. Gaunt SJ. Evolutionary shifts of vertebrate structures and Hox expression up and down the axial series of segments: a consideration of possible mechanisms. Int J Dev Biol. 2000; 44(1): 109-117, indexed in Pubmed: 10761855.

14. Gaunt SJ, Dean W, Sang H, et al. Evidence that Hoxa expression domains are evolutionarily transposed in spinal ganglia, and are established by forward spreading in paraxial mesoderm. Mech Dev. 1999; 82(1-2): 109-118, doi: 10.1016/s0925-4773(99)00018-0, indexed in Pubmed: 10354475.

15. Gaunt SJ, Strachan L. Temporal colinearity in expression of anterior Hox genes in developing chick embryos. Dev Dyn. 1996; 207(3): 270-280, doi: 10.1002/(SICl)10970177(199611)207:3<270::AID-AJA4>3.0.CO;2-E, indexed in Pubmed: 8922526.

16. Gilroy AM, MacPherson BR, Ross LM. Prometheus atlas of anatomy. Thieme Medical Publishers, New York 2008.

17. Hashimoto J, Murakami G, Tsugane MH, et al. Lumbosacral plexus in Hoxa9 knockout mice with special reference to their nerve variations identified according to whether they were interphenotypic or intergenotypic differences. Acta Anat Nippon. 1999; 74(6): 609-630, indexed in Pubmed: 10659578.

18. Hautier L, Weisbecker V, Sánchez-Villagra MR, et al. Skeletal development in sloths and the evolution of mammalian vertebral patterning. Proc Natl Acad Sci USA. 2010; 107(44): 18903-18908, doi: 10.1073/pnas.1010335107, indexed in Pubmed: 20956304.

19. Hirasawa K. Plexus brachialis und die Nerven der oberen Extremität. Arbeiten aus der dritten Abteilung des Anatomischen Institutes der Kaiserlichen Universität Kyoto, Series A 1931: 1-190.

20. Honma S, Kawai K, Koizumi M, et al. The superficial brachial artery passing superficially to the pectoral ansa, the highest superficial brachial artery (Arteria brachi- 
alis superficialis suprema). Anat Sci Int. 2011; 86(2): 108-115, doi: 10.1007/s12565-010-0094-2, indexed in Pubmed: 20963540.

21. Honma S, Tokiyoshi A, Kawai K, et al. Radial artery running beneath the biceps tendon and its interrelation between the radial recurrent arteries. Anat Sci Int. 2008; 83(4): 232-238, doi: 10.1111/j.1447-073X.2008.00231.x, indexed in Pubmed: 19159351.

22. Horwitz $M$. The anatomy of $(A)$ the lumbosacral nerve plexus?its relation to variations of vertebral segmentation and (B), the posterior sacral nerve plexus. Anat Rec. 1939; 74(1): 91-107, doi: 10.1002/ar.1090740110.

23. Ishiguro K, Kawashima T, Sato F. The phenotypic morphology of human lumbar plexus roots associated with changes in the thoracolumbar vertebral count and trade-off. Sci Rep. 2020; 10(1): 127, doi: 10.1038/s41598-019-56709-z, indexed in Pubmed: 31924812.

24. Iwanaga J, Singh V, Ohtsuka A, et al. Acknowledging the use of human cadaveric tissues in research papers: Recommendations from anatomical journal editors. Clin Anat. 2021; 34(1): 2-4, doi: 10.1002/ca.23671, indexed in Pubmed: 32808702.

25. Kawashima T, Thorington RW, Bohaska PW, et al. Variability and constraint of vertebral formulae and proportions in colugos, tree shrews, and rodents, with special reference to vertebral modification by aerodynamic adaptation. Folia Morphol. 2018; 77(1): 44-56, doi: 10.5603/ FM.a2017.0064, indexed in Pubmed: 28703847.

26. Kawashima T, Yoshitomi S, Sasaki H. Anatomical relationship between the superficial brachial arteries and the brachial plexus in humans, and their morphological significance. Folia Morphol. 2004; 63(4): 465-471, indexed in Pubmed: 15712145.

27. Knittel T, Kessel M, Kim MH, et al. A conserved enhancer of the human and murine Hoxa-7 gene specifies the anterior boundary of expression during embryonal development. Development. 1995; 121(4): 1077-1088, doi: 10.1242/ dev.121.4.1077, indexed in Pubmed: 7538068.

28. Kodama K. Arterial system. In: Sato T, Akita K ed. Anatomic variations in Japanese. University of Tokyo Press, Tokyo 2000: 220-237.

29. Kodama K, Yamada M, Kawai K, et al. The inferior pectoral artery, a new definition. Okajimas Folia Anat Jpn. 1987; 64(1): 47-57, doi: 10.2535/ofaj1936.64.1_47, indexed in Pubmed: 3601334.

30. Lance-Jones C, Landmesser L. Motoneurone projection patterns in the chick hind limb following early partial reversals of the spinal cord. J Physiol. 1980; 302: 581-602, doi: 10.1113/jphysiol.1980.sp013262, indexed in Pubmed: 7411470

31. Li ZL, Chisaka O, Koseki H, et al. Heat shock-induced homeotic transformations of the axial skeleton and associated shifts of Hox gene expression domains in mouse embryos. Reprod Toxicol. 1997; 11(6): 761-770, doi: 10.1016/ s0890-6238(97)00059-2, indexed in Pubmed: 9407586.

32. Loukas $M$, du Plessis M, Owens DG, et al. The lateral thoracic artery revisited. Surg Radiol Anat. 2014; 36(6): 543-549, doi: 10.1007/s00276-013-1234-x, indexed in Pubmed: 24281130

33. Moore KL, Dalley AF. Clinically oriented anatomy 5th ed. Lippincott Williams \& Wilkns, Philadelphia 2006.
34. Morikawa R. Course, distribution, and their variety of the nerves derived from the lumbar plexus to supply the abdominal wall. Acta Anat Nippon. 1971; 46: 312-338.

35. Narita Y, Kuratani S. Evolution of the vertebral formulae in mammals: a perspective on developmental constraints. J Exp Zool B Mol Dev Evol. 2005; 304(2): 91-106, doi: 10.1002/jez.b.21029, indexed in Pubmed: 15660398.

36. Natsis $K$, Piagkou M, Totlis $T$, et al. A prefix brachial plexus with two trunks and one anterior cord. Folia Morphol. 2020; 79(2): 402-406, doi: 10.5603/FM.a2019.0081, indexed in Pubmed: 31322725.

37. Ohuti H. Morfologia studo pri unu kazo de multapero de nervaj kaj muskolaj variacioj en ambaú malsupraj membroi. Acta Anat Nippon. 1951; 26: 32-42.

38. Olinger A, Benninger B. Branching patterns of the lateral thoracic, subscapular, and posterior circumflex humeral arteries and their relationship to the posterior cord of the brachial plexus. Clin Anat. 2010; 23(4): 407-412, doi: 10.1002/ca.20958, indexed in Pubmed: 20235185.

39. Orellana-Donoso M, Valenzuela-Fuenzalida J, Gold-Semmler $M$, et al. Neural entrapments associated with musculoskeletal anatomical variations of the upper limb: Literature review. Trans Res Anat. 2021; 22: 100094, doi: 10.1016/j.tria.2020.100094

40. Rijli FM, Matyas R, Pellegrini M, et al. Cryptorchidism and homeotic transformations of spinal nerves and vertebrae in Hoxa-10 mutant mice. Proc Natl Acad Sci USA. 1995; 92(18): 8185-8189, doi: 10.1073/pnas.92.18.8185, indexed in Pubmed: 7667266.

41. Standring S. Gray's anatomy. The anatomical basis of clinical practice. 41st ed. Elsevier, London 2016.

42. Tiret L, Le Mouellic H, Maury M, et al. Increased apoptosis of motoneurons and altered somatotopic maps in the brachial spinal cord of Hoxc-8-deficient mice. Development. 1998; 125(2): 279-291, doi: 10.1242/dev.125.2.279, indexed in Pubmed: 9486801.

43. Varela-Lasheras I, Bakker AJ, van der Mije SD, et al. Breaking evolutionary and pleiotropic constraints in mammals: On sloths, manatees and homeotic mutations. Evodevo. 2011; 2(1): 11, doi: 10.1186/2041-9139-2-11, indexed in Pubmed: 21548920.

44. Wolpert L. Positional information and the spatial pattern of cellular differentiation. J Theor Biol. 1969; 25(1): 1-47, doi: 10.1016/s0022-5193(69)80016-0.

45. Wellik DM. Hox patterning of the vertebrate axial skeleton. Dev Dyn. 2007; 236(9): 2454-2463, doi: 10.1002/ dvdy.21286, indexed in Pubmed: 17685480.

46. Xhakaza NK, Satyapal KS. Origin of the subscapular artery in the South African Black population. Folia Morphol. 2014; 73(4): 486-491, doi: 10.5603/FM.2014.0073, indexed in Pubmed: 25448908.

47. Yamada M. Significance of the superficial subscapular artery, new designation. Nihon lji-Shimpo. 1967; 60: 3-7.

48. Yang HJ, Gil YC, Lee HY. Intersegmental origin of the axillary artery and accompanying variation in the brachial plexus. Clin Anat. 2009; 22(5): 586-594, doi: 10.1002/ca.20811, indexed in Pubmed: 19484799.

49. Żytkowski A, Tubbs R, Iwanaga J, et al. Anatomical normality and variability: Historical perspective and methodological considerations. Trans Res Anat. 2021; 23: 100105, doi: 10.1016/j.tria.2020.100105. 